\title{
Analysis of flexible composites for coiled tubing applications
}

\author{
Kevin Cox \\ Christian Michelsen Research - Prototech AS \\ Fantoftvegen 38, Bergen, Norway, 5072
}

\begin{abstract}
Marina Menshykova ${ }^{1}$, Oleksandr Menshykov, Igor Guz
Centre for Micro- and Nanomechanics (CEMINACS), School of Engineering, University of Aberdeen, Aberdeen AB24 3UE, Scotland, UK
\end{abstract}

Key words: fiber-reinforced composites, stress and failure analysis, coiled tubing ABSTRACT

The present paper investigates thick-walled composite pipes subjected to simultaneous multi-axial loads common to those experienced in coiled tubing applications. The pipes were assumed to be filament wound carbon fiber-epoxy laminates with multiple layers and variable fiber orientations. MATLAB-based software was used to calculate stresses and carry out failure analyses through the thickness of the pipes when subjected to pressure, axial and bending (spooling) loads. Analyses were performed to determine if the composite tubes could achieve comparable strengths and spooling diameters as equivalent steel tube geometries.

\section{INTRODUCTION}

Composites are being increasingly recognized for their suitability in the most specific and demanding applications across many industries. Advantages of composite materials such as high specific strength-to-weight ratio, resistance to a wide range of fluids (including seawater, aerated water and hydrocarbons), which can attack metals, good thermal insulation, excellent damping and fatigue performance, and high strength and flexibility make them suitable candidates for use in the water environment for structural and nonstructural applications. These properties combined with the unmatched tailorability of the

${ }^{1}$ Corresponding author. Tel.: +44 1224 272782; e-mail: m.menshykova@abdn.ac.uk 
fibre-reinforced composite structures (stacking sequence, fibre volume ratio, etc. with natural limits imposed, for example, by over excessive bending or pressure) along load paths have motivated the industry to promote the use of composites in several critical loadbearing applications: particularly for risers, spoolable tubulars and tethers.

With the increasing length of boreholes, the use of steel coiled tubing faces the problem of weight increase, as the longer the pipe is then the thicker must be the walls to support its weight. In addition, the large strains induced during spooling push the steel beyond its yield point leading to low cycle use of the tubing. On the other hand, the composites are not as ductile as steels and consequently can't be pushed beyond their yield point. So, with the numerous advantages which composites have there are still some disadvantages the main of which are brakeage of inner fibres or crazes forming, that can lead to future fibre cracking. The primary loads driving the design of coiled tubing occur during installation: bending around a reel during spooling and unspooling, and operation: axial loads and internal/external pressure occurring after the tubing has been deployed down-hole. Other loads such as thermal expansion/contraction, local radial compression and impact are also important for coiled tubing design but are less significant from a global optimization perspective. A detailed description of coiled tubing loads is provided in [1] which presents a basic differential equation pair (originally from [2]) that is integrated over the tubing segment and includes the influences of well bore curvature, buoyancy, friction, torsional motion and other effects.

Coiled tubes fabricated with composites allow for extended working depths as they have advantages such as low density, high strength and flexibility when compared to steel. Composite tubing of this type however experiences matrix cracking during use and requires a thermoplastic liner to be implemented (at the inner diameter). The coiled tube itself is a thick-walled pipe of several kilometers length. Consequently, continuous manufacturing processes such as pultrusion, pull winding or pull braiding technique needed for fiber reinforced composite coiled tubing fabrication.

The topic of the present paper was to investigate thick-walled composite pipes subjected to multi-axial loads common to those experienced in coiled tubing applications. Previously, a number of other studies have been conducted on this topic. A comprehensive review on composite pipe applications in the oil and gas industry is provided in [3] which also presents stress and failure calculations for thick-walled fiber reinforced pipes under external pressure.

The study in [4] considered filament-wound pipes at six different fiber angles under different types of loading: biaxial pressure, hoop pressure and tensile loading, and achieved good 
agreement with classical lamination theory. The combined load of tension and internal pressure subjected to reinforced thermoplastic pipes was studied in [5]. An analytical solution for design and analysis of laminated composite tubes was defined in [6]. A simplified elastic solution to analyze the stress and deformation of multi-layered filament-wound composite pipes under internal pressure was presented in [7]. Stress and deformation analyses were carried out in [8], leading to the presentation of two analytical methods based on curved composite beam and multilayer-buildup theories which were compared with experimental data. The study in [9] presented an evaluation on the behavior of filamentwound spoolable composites though a combination of 4-point bending tests and FEA to determine minimum spool radii.

More recently, the stress distributions in spoolable fiber reinforced composite pipes were investigated in [10] comparing stresses in filament wound pipes with and without an inner metal layer. Bending stiffness of composite tubes is considered in [11, 12] where the theoretical formulation for bending stiffness using non-classical composite beam theory has been presented and comparison with experimental data was given. Multi-layered fiber reinforced thick cylinders under combined axial load, inner and outer pressure was considered in [13] where the analytically obtained stresses and deformations were compared with finite element results. The effect of stacking sequence, fibre volume fraction and fibre alignment on flexural properties of carbon and glass fibre reinforced composites could be found in $[14,15]$.

The work of the current paper investigates thick-walled (radial stress becomes significant when the wall thickness exceeds $1 / 20$ of the diameter) composite pipes with variable fiber orientation angles, diameters and wall thicknesses subjected individually and simultaneously to pressure and axial loads. In addition, bending loads were calculated to determine tolerable spooling diameters. Through-thickness stress distribution and failure coefficient of the tubes were calculated based on the composite layup. The pipes were assumed to be filament-wound carbon fiber-epoxy laminates.

\section{ANALYSIS METHODS}

Because of how composites are fabricated, they can be engineered to meet the specific demands for each particular application. In the case of coiled tubing, changing the fiber orientations, number of layers in a given direction, thickness of individual layers and layer stacking sequence, can tailor the properties of the pipe to fulfill the load requirements. 
To design a pipe suitable for a coiled tubing well application the steps described herein were taken. Failure calculations were performed to determine the stresses within the wall of a given pipe and were readily available based on different types of individual and simultaneous loading types: pressure, axial force, torque and temperature. Consequently, a suitable composition of the material (fiber and matrix volume fraction), lay-up of the pipe, and pipe geometry to withstand the loads was determined. Thereafter, the stiffness could be calculated which permitted ranking the acceptable pipes according to their stiffnesses; the pipe must be stiff enough to be pushed into the well. Finally, the bending stress/strain calculations were performed to yield the minimum spooling diameter. This process is outlined in Figure 1.

\subsection{Failure Calculation}

The software implemented for failure calculation in this study was based on the elasticity solution for laminated circular tubes as described in [3], [7], [16] and [17]. The MATLABbased software allowed for calculation of the stresses and failure coefficient at any point in the pipe when exposed to inner/outer pressure, axial force, torque and thermal loads. For the current investigation, the effects of temperature were not included to simplify the analysis of the considered multi-parametrical problem (thermal expansion/contraction must be considered separately). The structure of the software is shown in Figure 2.

As we solve the problem analytically, to find stresses in the pipe subjected to inner, outer pressure and axial force the system of equations which consists of boundary conditions, continuity conditions, axial force and torque must be solved.

The boundary conditions for the $\mathrm{N}$ layers laminated tube with inner and outer radii $r_{0}$ and $r_{a}$ subjected to outer and inner pressure $p_{0}$ and $p_{a}$ has the form [16]:

$$
\begin{gathered}
\sigma_{r}^{(1)}\left(r_{0}\right)=-p_{0}, \sigma_{r}^{(N)}\left(r_{a}\right)=-p_{a}, \\
\tau_{\theta r}^{(1)}\left(r_{0}\right)=\tau_{z r}^{(1)}\left(r_{0}\right)=0, \tau_{\theta r}^{(N)}\left(r_{0}\right)=\tau_{z r}^{(N)}\left(r_{0}\right)=0,
\end{gathered}
$$

where $\sigma_{r}^{(1)}$ and $\sigma_{r}^{(N)}$ are radual stresses on first and $N$-th layers; $\tau_{\theta r}$ and $\tau_{z r}$ are shear stresses.

Displacements in the pipe must be continuous from layer to layer as the layers are perfectly bonded. The continuity conditions for the considered problem have the following form [7]:

$$
\tau_{\theta r}^{(k)}\left(r_{0}\right)=\tau_{z r}^{(k)}\left(r_{0}\right)=0, \quad k=\overline{1, N},
$$




$$
u_{r}^{(k)}\left(r_{k}\right)=u_{r}^{(k+1)}\left(r_{k}\right), \sigma_{r}^{(k)}\left(r_{k}\right)=\sigma_{r}^{(k+1)}\left(r_{k}\right), \quad k=\overline{1, N-1}
$$

where $u_{r}^{(k)}$ is a radial displacement and $r_{k}$ is an outer radius of the $k$-th layer.

The axial force, $F_{a x i a l}$, at the end of the tube is determined by integrating the axial stress over the area of cross section [16]:

$$
2 \pi \sum_{k=1}^{N} \int_{r_{k-1}}^{r_{k}} \sigma_{z}^{(k)}(r) d r=F_{\text {axial }} .
$$

The torque, $T$, can be determined by integrating the moment of the shear stress $\tau_{z \theta}$ over the cross-sectional area of the tube [16]:

$$
2 \pi \sum_{k=1}^{N} \int_{r_{k-1}}^{r_{k}} \tau_{z \theta}^{(k)}(r) r^{2} d r=T
$$

The expressions for displacement and layered stressed have the following form [16] with unknown $A, B, \varepsilon_{0}$ and $\gamma_{0}$ :

$$
\begin{gathered}
u_{r}^{(k)}=A^{(k)} r^{\beta(k)}+B^{(k)} r^{-\beta(k)}+\alpha_{1}^{(k)} \varepsilon_{0} r+\alpha_{2}^{(k)} \gamma_{0} r^{2} \\
\tau_{\theta r}^{(k)}=\tau_{r z}^{(k)}=0, \\
\tau_{z \theta}^{(k)}=\left[\bar{C}_{16}^{(k)}+\left(\bar{C}_{26}^{(k)}+\bar{C}_{36}^{(k)}\right) \alpha_{1}^{(k)}\right] \varepsilon_{0}+\left[\bar{C}_{66}^{(k)}+\left(\bar{C}_{26}^{(k)}+2 \bar{C}_{36}^{(k)}\right) \alpha_{2}^{(k)}\right) \gamma_{0} r \\
+\left(\bar{C}_{26}^{(k)}+\beta(k) \bar{C}_{36}^{(k)}\right) A^{(k)} r^{\beta(k)-1}+\left(\bar{C}_{26}^{(k)}-\beta(k) \bar{C}_{36}^{(k)}\right) B^{(k)} r^{-\beta(k)-1}, \\
\sigma_{z}^{(k)}=\left[\bar{C}_{11}^{(k)}+\left(\bar{C}_{13}^{(k)}+\bar{C}_{12}^{(k)}\right) \alpha_{1}^{(k)}\right) \varepsilon_{0}+\left[\bar{C}_{16}^{(k)}+\left(\bar{C}_{12}^{(k)}+2 \bar{C}_{13}^{(k)}\right) \alpha_{2}^{(k)}\right) y_{0} r \\
+\left(\bar{C}_{12}^{(k)}+\beta(k) \bar{C}_{13}^{(k)}\right) A^{(k)} r^{\beta(k)-1}+\left(\bar{C}_{12}^{(k)}-\beta(k) \bar{C}_{13}^{(k)}\right) B^{(k)} r^{-\beta(k)-1}, \\
\sigma_{\theta}^{(k)}=\left[\bar{C}_{12}^{(k)}+\left(\bar{C}_{22}^{(k)}+\bar{C}_{23}^{(k)}\right) \alpha_{1}^{(k)}\right) \varepsilon_{0}+\left[\bar{C}_{26}^{(k)}+\left(\bar{C}_{22}^{(k)}+2 \bar{C}_{23}^{(k)}\right) \alpha_{2}^{(k)}\right) y_{0} r \\
+\left(\bar{C}_{22}^{(k)}+\beta(k) \bar{C}_{23}^{(k)}\right) A^{(k)} r^{\beta(k)-1}+\left(\bar{C}_{22}^{(k)}-\beta(k) \bar{C}_{23}^{(k)}\right) B^{(k)} r^{-\beta(k)-1}, \\
\sigma_{r}^{(k)}=\left[\bar{C}_{13}^{(k)}+\left(\bar{C}_{23}^{(k)}+\bar{C}_{33}^{(k)}\right) \alpha_{1}^{(k)}\right] \varepsilon_{0}+\left[\bar{C}_{36}^{(k)}+\left(\bar{C}_{23}^{(k)}+2 \bar{C}_{33}^{(k)}\right) \alpha_{2}^{(k)}\right) y_{0} r \\
+\left(\bar{C}_{23}^{(k)}+\beta(k) \bar{C}_{33}^{(k)}\right) A^{(k)} r^{\beta(k)-1}+\left(\bar{C}_{23}^{(k)}-\beta(k) \bar{C}_{33}^{(k)}\right) B^{(k)} r^{-\beta(k)-1} .
\end{gathered}
$$

where $\bar{C}_{i j}$ are off-axis stiffness constants;

$$
\beta^{(k)}=\sqrt{\frac{\bar{C}_{22}^{(k)}}{\bar{C}_{33}^{(k)}}}, \quad \alpha_{1}^{(k)}=\frac{\bar{C}_{12}^{(k)}-\bar{C}_{13}^{(k)}}{\bar{C}_{33}^{(k)}-\bar{C}_{22}^{(k)}}, \quad \alpha_{2}^{(k)}=\frac{\bar{C}_{26}^{(k)}-2 \bar{C}_{36}^{(k)}}{4 \bar{C}_{33}^{(k)}-\bar{C}_{22}^{(k)}} .
$$

After substitution of the expression for displacement and layer stresses (5) into boundary (1) and continuity (2) conditions and expressions for axial force and torque (3), (4) we obtain 
system of equastions [3], which in matrix form is given in Appendix. Solving this system the stresses in pipe can be obtained.

To calculate failure axial $\sigma_{z}$, hoop $\sigma_{\theta}$ and shear $\tau_{z \theta}$ stresses in pipe are transformed into stresses in principal material directions:

$$
\left[\begin{array}{l}
\sigma_{1} \\
\sigma_{2} \\
\sigma_{3}
\end{array}\right]=\left[\begin{array}{ccc}
m^{2} & n^{2} & 2 m n \\
n^{2} & m^{2} & -2 m n \\
-m n & m n & m^{2}-n^{2}
\end{array}\right]\left[\begin{array}{c}
\sigma_{z} \\
\sigma_{\theta} \\
\tau_{z \theta}
\end{array}\right],
$$

where $m=\cos \theta, n=\sin \theta$ ( $\theta$ is the angle between the pipe axis and filament).

The Tsai-Hill failure criterion was implemented for the composite tubes. According to the criterion, failure occurs when the failure coefficient (FC) becomes greater than 1 :

$$
F C<1 \rightarrow \text { no failure } \quad F C \geq 1 \rightarrow \text { failure }
$$

It is generally recognized that the Tsai-Hill criterion underestimates the failure stress because the transverse tensile strength of a unidirectional lamina is generally much less than its transverse compressive strength, and the compressive strengths are not used in the Tsai-Hill failure theory. Thus, the modified form of Tsai-Hill (7) formulated in [18] was implemented; under off-axis tensile loading, it agrees with the original formula, however it takes a modified form for off-axis compressive loading:

$$
\begin{gathered}
F C=\frac{\sigma_{1}^{2}}{X_{T}^{2}}-\frac{\sigma_{1} \sigma_{2}}{X_{T}^{2}}+\frac{\sigma_{2}^{2}}{Y_{T}^{2}}+\frac{\tau_{12}^{2}}{S^{2}}, \text { if } \sigma_{2}>0 ; \\
F C=\frac{\sigma_{1}^{2}}{X_{C}^{2}}-\frac{\sigma_{1} \sigma_{2}}{X_{C}^{2}}+\frac{\sigma_{2}^{2}}{Y_{C}^{2}}+\frac{\tau_{12}^{2}}{\left(S-\mu_{L} \sigma_{2}\right)^{2}}, \text { if } \sigma_{2}<0,
\end{gathered}
$$

where $\mu_{L}$ is a material constant that characterizes the in-plane shear strength differential effect.

\subsection{Stiffness and Bending Calculations}

The bending stresses in the composite pipes were calculated using the analytical approach presented in [19]. Stresses in the multi-layered thick walled fibre reinforced pipe can be obtained solving the system of equations which consists of boundary conditions, continuity conditions and equilibrium for bending moment. 
As the pipe spooled on the drum subjected to no internal or external pressure the boundary conditions have the following form:

$$
\sigma_{r}^{(1)}\left(r_{0}\right)=0, \quad \sigma_{r}^{(N)}\left(r_{a}\right)=0 .
$$

The layers of the pipe are perfectly bonded, so the continuity conditions for displacements and stresses on the layer interfaces are as follows:

$$
\begin{gathered}
u_{r}^{(k)}\left(r_{k}\right)=u_{r}^{(k+1)}\left(r_{k}\right), \\
u_{\theta}^{(k)}\left(r_{k}\right)=u_{\theta}^{(k+1)}\left(r_{k}\right), \\
\sigma_{r}^{(k)}\left(r_{k}\right)=\sigma_{r}^{(k+1)}\left(r_{k}\right) \quad k=\overline{1, N-1},
\end{gathered}
$$

where $N$ is the number of layers and $u_{\theta}^{(k)}$ is a hoop displacement of the $k$-th layer.

The equilibrium for bending moment is satisfied by the relation [20]:

$$
\iint_{\theta} \sigma_{z} r^{2} \sin \theta d r d \theta=M \quad r \in\left[r_{0}, r_{a}\right] \quad \theta \in[0,2 \pi],
$$

where $M$ is bending moment.

The components of the stress field [19] have the form:

$$
\begin{gathered}
\sigma_{r}=\left(B r^{-1+\beta}-C r^{-1-\beta}+A \eta r\right) \sin \theta, \\
\sigma_{\theta}=\left[B(1+\beta) r^{-1+\beta}-C(1-\beta) r^{-1-\beta}+3 A \eta r\right] \sin \theta, \\
\tau_{r \theta}=-\left(B r^{-1+\beta}-C r^{-1-\beta}+A \eta r\right) \cos \theta, \\
\sigma_{z}=\left(s_{1} B r^{-1+\beta}+s_{2} C r^{-1-\beta}+s_{3} A r\right) \sin \theta,
\end{gathered}
$$

where $A, B$ and $C$ are unknowns, $S_{i j}$ are compliance constants,

$$
\begin{array}{cc}
\beta=\sqrt{1+\frac{R_{11}+2 R_{12}+R_{44}}{R_{22}},} & \eta=\frac{S_{23}-S_{13}}{R_{11}+2 R_{12}+R_{44}-3 R_{22}}, \\
s_{1,2}=\mp \frac{S_{13}+S_{23}(1 \pm \beta)}{S_{33}}, & S_{3}=1-\frac{\left(S_{13}+3 S_{23}\right) \eta}{S_{33}}, \\
R_{i j}=S_{i j}-\frac{S_{i 3} S_{j 3}}{S_{33}} & i, j=1,2,4 .
\end{array}
$$

Radial and hoop displacements are presented as follow [19]: 


$$
\begin{gathered}
u_{r}=\left(p_{1} B r^{\beta}+p_{2} C r^{-\beta}+p_{3} A r^{2}\right) \sin \theta, \\
u_{\theta}=\left(q_{1} B r^{\beta}+q_{2} C r^{-\beta}+q_{3} A r^{2}\right) \cos \theta,
\end{gathered}
$$

where

$$
\begin{gathered}
p_{1,2}=\frac{R_{11}+R_{12}(1 \pm \beta)}{\beta}, \quad p_{3}=\frac{\left(R_{11}+3 R_{12}\right) \eta+S_{13}}{2}, \\
q_{1,2}=\frac{R_{11}+R_{12} \mp R_{22} \beta(1 \pm \beta)}{\beta}, \quad q_{3}=\frac{\left(R_{11}+R_{12}-6 R_{22}\right) \eta+S_{13}-2 S_{23}}{2} .
\end{gathered}
$$

Substituting layer stresses (11) and displacements (12) into expressions above (8)-(10) we will derive the system of equations. MATLAB was used to generate the stress and failure calculations following the general structure shown in Figure 2. Following this method the software produced a stress field around the circumference of the pipe and through the thickness of every individual ply layer. The stress distribution is the result of any given bending moment (input), and since the tubing is subjected to a moment that conforms it to the drum, the drum radius $R$ must be found. The bending moment was calculated using classical theory and is described below:

$$
M=E I K
$$

where $M$ is bending moment, $K$ is curvature, $E$ is Young's modulus, $I$ is the second moment of inertia.

For a tube of circular cross-section equation (13) has the form:

$$
M=\frac{\pi}{4}\left(r_{a}^{4}-r_{0}^{4}\right) E K
$$

where $r_{a}$ is outer pipe radius, $r_{0}$ is inner pipe radius, $K=1 / R$, and $R$ is the drum radius.

The Young's modulus is the ratio of stress to strain in loading direction. As in laminate the strain will be the same for all plies for the load applied along the plies, knowing Young's modulus for every ply in the loading direction, the stress in each ply can be expressed in terms of this strain.

Axial Young's modulus of the lamina can be found as follows [16]:

$$
E_{x}^{(k)}=\frac{E_{1}}{\left[m^{4}+m^{2} n^{2}\left(-2 v_{12}+\frac{E_{1}}{G_{12}}\right)+n^{4} \frac{E_{1}}{E_{2}}\right]},
$$


where $E_{1}$ is longitudinal and $E_{2}$ is transverse Young's modulus of the unidirectional composite, $m=\cos \varphi, n=\sin \varphi$, and $\varphi$ is the fiber orientation angle.

The stress in each ply can be expressed in terms of the strain, $\varepsilon_{x}$ :

$$
E_{x}^{(k)}=\frac{\sigma_{x}^{(k)}}{\varepsilon_{x}} \quad \Rightarrow \quad \sigma_{x}^{(k)}=E_{x}^{(k)} \mathcal{E}_{x} .
$$

Furthermore, the force (stress times sectional area) represented by the applied stress can also be expressed as the sum of the forces being carried by each ply.

$$
F^{(k)}=\sigma^{(k)} A^{(k)},
$$

where

$$
A^{(k)}=\pi\left(r_{k}^{2}-r_{k-1}^{2}\right), \quad F=\sum_{k=1}^{N} F^{(k)} .
$$

This allows the overall Young's modulus of the laminate to be calculated:

$$
E=\frac{F / A}{\varepsilon_{x}}
$$

where

$$
A=\pi\left(r_{a}^{2}-r_{0}^{2}\right) .
$$

Consequently, by knowing the laminate Young's modulus and the bending stiffness, the bending moment for different drum radii can be solved for.

\section{NUMERICAL STUDIES}

\subsection{Material Properties and Loads Definition}

The numerical analyses performed in this study assumed filament wound pipes composed of carbon/epoxy composite T300/LY5052 [17]. The material properties are provided in Table 1 together with the properties of steel (a standard coiled tubing material) for comparison.

As discussed above, the stresses in coilable tubes arise during spooling under bending load. However, there are other important loads the tubes must resist during operation, namely pressure and axial loads. Internal and external pressures with difference from 60 up to 100 $\mathrm{MPa}$ are common in the industry [21] and axial loads due to self-weight and freely-hanging equipment attached to the end of the tubing must also be supported (please see the details of the simplified model used in the current study below). Other factors such as buoyancy, 
well bore wall friction, and fluid (flow) friction also contribute to operational loads but have not been considered here. To understand the performance of composite tubes, simultaneous exposure to pressure and axial loads (with bending equal to zero) must be realized as a first load case. The composite pipes must also survive a second load case from spooling (bending) the tube around the hub (with pressure and axial loads being equal to zero under storage conditions).

For the first load case, pressures of 60 and $100 \mathrm{MPa}$ were defined and were applied to the pipes at the differentials specified in Table 2, all which resulted in net outer pressure.

Regarding axial loading, a simplistic approach was taken; the composite tubes were required to withstand $1000 \mathrm{~m}$ of their freely-hanging length with no support from wall friction, slanted/horizontal wells shapes, or buoyancy, and no influence from internal fluid weight, tool weight, or dynamic deployment/retraction loads. More detailed explanations of axial loads including wall friction, fluid friction, axial compression, and buckling in deployed coiled tubing systems can be found in [1] and [2].

\subsection{Analyses Performed}

Two sets of analyses were conducted in this work and are described in the following section. The first set of analyses studied composite pipes of three OD with different wall thicknesses under pressure and axial load. The size of the tubing was chosen to better match common coiled tubing strings with outer diameters ranging from 50.8 to $66.7 \mathrm{~mm}$ (Table 3 ). Six layups were studied for each pipe: with fibers oriented to $[+\theta /-\theta],[0 / 0 /+\theta /-\theta],[0 / 0 /+\theta /-\theta /+\theta /-\theta],[+\theta /-$ $\theta / 0 / 0 /+\theta /-\theta],[+\theta /-\theta / 0 / 0]$ and $[+\theta /-\theta /+\theta /-\theta / 0 / 0]$ angles with respect to the longitudinal pipe axis. These lay-ups were chosen to find out how the position of 0-layer influences the strength of the pipe. Failure coefficient plots dependent on fibre angle and point on the wall were plotted for different tube sizes and layups when subjected to inner and outer pressure difference of 60 and $100 \mathrm{MPa}$, and pressure plus axial load (1000m free-hanging length) as presented in the results Section 4.1.

In addition to fulfilling the pressure and axial load requirements, the bending calculations described above were performed to determine the allowable spooling diameter of the acceptable (non-failing) pipe layups. Consequently, a bending radius requirement of $1.42 \mathrm{~m}$, a standard spooling size [21], was set.

Based on the results from the first and second analysis sets, a third and final study was performed with a more complex laminate. The laminate took the form of $[55 /-55 / 10 /-10 /+\theta /-$ 
$\theta]$, and the failure coefficient was calculated for the 50.8/39.4 $\mathrm{mm}$ (OD/ID) pipe with the above stated pressure and axial loads. The longitudinal, transverse (circumferential) and shear stresses were also generated for the bending load case and are presented.

\section{RESULTS AND DISCUSSION}

\subsection{Analysis Set 1 (pressure and axial load)}

The results for analysis set 1 are summarized in Table 4 and Table 5, which indicate the allowable fiber orientations for each pipe based on applied loads. Figures 3-5 shows the failure coefficient distribution for the pipes of different lay-ups under inner and outer pressure. We can see that the distributions for these cases are similar, however $[\theta /-\theta]$ layup is smoother than the one with $0^{0}$ layers.

Table 6 shows the influence that the pressure and axial loads have individually and simultaneously on the failure coefficient and acceptable winding angles. Regarding pressure, the fiber angles nearest $90^{\circ}$ provided the most resistance, while the opposite was true for the axial load as was expected. To best restrain the axial loads, fiber orientations nearest to $0^{\circ}$ were desired. Comparing Figures $6 \mathrm{a}$ and $6 \mathrm{~b}$, it can be seen that only a small region of winding angles between about $35^{\circ}$ and $65^{\circ}$ satisfy both loading types. However, as shown in Figure 6c, when the loads were applied simultaneously, the axial stress state exceeded the allowable limit as defined in equation (7). The inability of the $[\theta /-\theta]$ layup to withstand the axial load was independent of pipe geometry.

Consequently, to withstand three types of loading (inner and outer pressure and axial force) $0^{0}$ layer must be added (Figure 7).

The $0^{\circ}$ layers had a significant influence on the failure coefficient, and with respect to the axial load alone the pipe was likely overdesigned (Figure 8 ). The dominant factors regarding pressure resistance however were the magnitude of the pressure load, pipe diameter and wall thickness. Including $0^{\circ}$ fibers allowed for satisfaction of the simultaneous pressure and axial load condition.

\subsection{Analysis set 2 (bending load)}

In this part the analysis of three tubes of different geometries and six layups under bending loading are summarised in Table 6, where suitable angles to spool the tube on the drum 
with $1.42 \mathrm{~m}$ radius are shown. In Table 7 the Young's modulus and bending stiffness for pipes of various lay-ups could be found.

If we compare the angle suitable for bending loading with the one from previous sections, then we will get the layups, which makes the tubes be spooled on the drum with $1.42 \mathrm{~m}$ radius and withstand pressure difference of $60 \mathrm{MPa}$, with $10 \mathrm{MPa}$ inner pressure (Table 8). As we can see the lay-ups without 0-layer and with inner 0-layer could not withstand the loads.

Figures 9-11 shows longitudinal, transverse and shear stresses for pipes of different layups, which can withstand bending and pressure loads.

To withstand pressure difference of $100 \mathrm{MPa}$ the layup of the pipe should be more complicated, than those that were initially considered. The results for $50.8 \mathrm{~mm}$ OD pipe with a layup of $[55 /-55 / 10 /-10 / \theta /-\theta]$ are presented in Figure 12. For the pipe under outer pressure loading of $100 \mathrm{MPa}$ and axial force the suitable layups for spooling on the drum of $1.42 \mathrm{~m}$

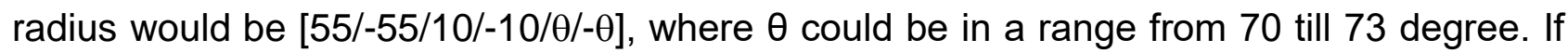
we add inner pressure of $10 \mathrm{MPa}$, keeping the pressure difference of $100 \mathrm{MPa}$, then suitable layup will be [60/-60/10/-10/ $\theta /-\theta]$, where $\theta$ could be in a range from 72 till 75 degree.

As we can see, for some cases the layup of the pipe became quite complicated with very limited range of the allowable angles.

\section{CONCLUSIONS}

Thick-walled composite pipes subjected to pressure, axial and bending loads were investigated in this work. Different pipe geometries, composite layup definitions and fiber angle orientations were studied to investigate the sensitivity of these variables on the pipes strength. Numerical simulations were performed with MATLAB-based software which provided through-thickness stress distributions, pipe stiffnesses and failure coefficients allowing for several top-level conclusions to be drawn from the results.

Pressure and axial loads drive the need for hoop and longitudinal strength respectively, while the tube spooling diameter induces high bending stresses requiring flexibility. Advanced layups with multiple fiber orientations are necessary to simultaneously fulfill the pressure, axial load and bending capabilities achieved by equivalent-geometry steel tubes. Based on the design requirements specified in this work, the composite tubes were capable 
of matching the performance of comparable steel tubes, and it is likely that further optimization could improve the margin on these results.

\section{Acknowledgements}

The financial support of provided by Regionale Foskningsfond - Vestlandet (Norway) is gratefully acknowledged.

\section{References}

[1] Newman K, Bhalla K, McSpadden A. Basic Tubing Forces Model (TFM) Calculation. CTES, L.P., Conroe, 2003.

[2] Bhalla K. Implementing Residual Bend in a Tubing Forces Model. In SPE 28303, 69th ATCE, New Orleans, September 1994.

[3] Guz IA, Menshykova MV, Paik JK. 2015. Thick-walled composite tubes for offshore applications: an example of stress and failure analysis for filament-wound multi-layered pipes. Ships and Offshore Structures 2015; 12(3): 304-322.

[4] Rosenow MWK. 1984. Wind angle effects in glass fiber-reinforced polyester filament wound pipes. Composites 1984; 15: 144-52.

[5] Qiao H, Zhang Y, Bai Y, Cheng P, Lu Y, Han P, Tang G. Study on reinforced thermoplastic pipe under combined tension and internal pressure. Ships and Offshore Structures 2018; 13(1): 86-97.

[6] J.M. Starbuck, C. Eberle. Analytical solution for the design of spoolable composite tubing. Third International Conference on Composite Materials for Offshore Operations. Houston, TX, October 31 - November 22000.

[7] Xia M, Takayanagi H, Kemmochi K. Analysis of multi-layered filament-wound composite pipes under internal pressure. Composite Structures 2001; 53: 483491.

[8] Xia M, Takayanagi H, Kemmochi K. Analysis of filament-wound fibre-reinforced sandwich pipe under combined internal pressure and thermomechanical loading. Composite Structures 2001; 51: 273-283. 
[9] Rodriguez DE, Ochoa OO. Flexural response of spoolable composite tubulars: an integrated experimental and computational assessment. Composite Science and Technology 2004; 64(13-14): 2075-2088.

[10] Menshykova MV, Guz IA. Stress analysis of layered thick walled composite pipes subjected to bending loading. International Journal of Mechanical Sciences 2014; 88: 289-299.

[11] Shadmehri F, Derisi B, Hoa SV. On bending stiffness of composite tubes. Composite Structures 2011; 93: 2173-2179.

[12] Geuchy Ahmad MI, Hoa SV Flexural stiffness of thick walled composite tubes. Composite Structures 2016; 149: 125-133.

[13] Xing J, Geng P, Yang T. Stress and deformation of multiple winding angle hybrid filament-wound thick cylinder under axial and internal and external pressure. Composite Structures 2015; 131: 868-877.

[14] Kalantari M, Dong C, Davies IJ. 2017. Multi-objective robust optimization of multidirectional carbon/glass fibre-reinforced hybrid composites with manufacture related uncertainties under flexural loading. Composite Structures 2017; 182: 132142.

[15] Dong C, Davies IJ. 2018. Effect of stacking sequence on the flexural properties of carbon and glass fibre-reinforced hybrid composites. Advanced Composites and Hybrid Materials 2018; 1(3): 530-540.

[16] Herakovich C. Mechanics of fibrous composites. John Wiley and Sons, Inc, 1998

[17] Bakaiyan $\mathrm{H}$, Hosseini $\mathrm{H}$, Ameri E. Analysis of multi-layered filament-wound composite pipes under combined internal pressure and thermomechanical loading with thermal variations. Composite Structures 2009; 88: 532-541.

[18] Kawai M, Saito S. Off-axis strength differential effects in unidirectional carbon/epoxy laminates at different strain rates and predictions of associated failure envelopes. Composites: Part A 2009; 40: 1632-1649.

[19] Natsuki T, Takayanagi $\mathrm{H}$, Tsuda $\mathrm{H}$. Prediction of bending strength for filamentwound composite pipes. Journal of Reinforced Plastics and Composites 2003; 22(8): 695-710. 
[20] Xia M, Takayanagi $\mathrm{H}$, Kemmochi $\mathrm{K}$. Bending behavior of filament-wound fibrereinforced sandwich pipes. Composite Structures 2002; 56: 201-210.

[21] Quality Tubing - NOV, Technical Manual, Quality Tubing Products. D932000051MAN-001 Rev. 04. National Oilwell Varco; 2014.

\section{Appendix}

The system of equations for stresses derivation, consisting of boundary conditions, continuity conditions, axial force and torque, could be presented in a matrix form as follow [3]:

$$
X F=Z
$$

where $X, F$ and $Z$ are

$$
Z=\left[\begin{array}{c}
-p_{0} \\
0 \\
0 \\
\vdots \\
0 \\
0 \\
-p_{a} \\
F_{\text {axial }} \\
T
\end{array}\right] \quad X=\left[\begin{array}{l}
X(1) \\
* \\
X(N) \\
X(N+1) \\
\bullet \\
X(2 N) \\
X(2 N+1) \\
X(2 N+2)
\end{array}\right] \begin{aligned}
& X(1)=A^{(1)} \\
& X(N)=A^{(N)} \\
& X(2 N)=B^{(N)} \\
& X(2 N+1)=\varepsilon_{0} \\
& X(2 N+2)=\gamma_{0}
\end{aligned}
$$




$\left[\begin{array}{cccccccccc}F(1,1) & 0 & 0 & 0 & F(1, N+1) & 0 & 0 & 0 & F(1,2 N+1) & F(1,2 N+2) \\ * & * & 0 & 0 & * & * & 0 & 0 & * & * \\ 0 & F(k, k) & F(k, k+1) & 0 & 0 & F(k, N+k) & F(k, N+k+1) & 0 & F(k, 2 N+1) & F(k, 2 N+2) \\ 0 & 0 & * & * & 0 & 0 & * & * & * & * \\ \circ & \circ & 0 & 0 & \circ & \circ & 0 & 0 & \circ & \circ \\ 0 & F(N+k, k) & F(N+k, k+1) & 0 & 0 & F(N+k, N+k) & F(N+k, N+k+1) & 0 & F(N+k, 2 N+1) & F(N+k, 2 N+2) \\ 0 & 0 & \circ & \circ & 0 & 0 & \circ & \circ & \circ & \circ \\ 0 & 0 & 0 & F(2 N, N) & 0 & 0 & 0 & F(2 N, 2 N) & F(2 N, 2 N+1) & F(2 N, 2 N+2) \\ \bullet & F(2 N+1, k) & \bullet & \bullet & \otimes & F(2 N+1, N+k) & \otimes & \otimes & F(2 N+1,2 N+1) & F(2 N+1,2 N+2) \\ \oplus & F(2 N+2, k) & \oplus & \oplus & \times & F(2 N+2, N+k) & \times & \times & F(2 N+2,2 N+1) & F(2 N+2,2 N+2)\end{array}\right]$




$$
\begin{aligned}
& k=\overline{1, N-1} \\
& F(1,1)=\left(\bar{C}_{23}^{(1)}+\beta(1) \bar{C}_{33}^{(1)}\right) r_{0}^{\beta(1)-1} \quad F(1, N+1)=\left(\bar{C}_{23}^{(1)}-\beta(1) \bar{C}_{33}^{(1)}\right) r_{0}^{\beta(1)-1} \\
& F(1,2 N+1)=\bar{C}_{13}^{(1)}+\left(\bar{C}_{23}^{(1)}+\bar{C}_{33}^{(1)}\right) \alpha_{1}^{(1)} \quad F(1,2 N+2)=\left[\left(\bar{C}_{23}^{(1)}+2 \bar{C}_{33}^{(1)}\right) \alpha_{2}^{(1)}+\bar{C}_{36}^{(1)}\right] r_{0} \\
& F(k, k)=r_{k}^{\beta(k)} F(k, k+1)=-r_{k}^{\beta(k+1)} \quad F(k, N+k)=r_{k}^{-\beta(k)} \quad F(k, N+k+1)=-r_{k}^{-\beta(k+1)} \\
& F(k, 2 N+1)=\left(\alpha_{1}^{(k)}-\alpha_{1}^{(k+1)}\right) r_{k} F(k, 2 N+2)=\left(\alpha_{2}^{(k)}-\alpha_{2}^{(k+1)}\right) r_{k}^{2} \\
& F(N+k, k)=\left(\bar{C}_{23}^{(k)}+\beta(k) \bar{C}_{33}^{(k)}\right) r_{k}^{\beta(k)-1} \\
& F(N+k, k+1)=-\left(\bar{C}_{23}^{(k+1)}+\beta(k+1) \bar{C}_{33}^{(k+1)}\right) r_{k}^{\beta(k+1)-1} \\
& F(N+k, k)=\left(\bar{C}_{23}^{(k)}-\beta(k) \bar{C}_{33}^{(k)}\right) r_{k}^{-\beta(k)-1} \\
& F(N+k, k+1)=-\left(\bar{C}_{23}^{(k+1)}-\beta(k+1) \bar{C}_{33}^{(k+1)}\right) r_{k}^{-\beta(k+1)-1} \\
& F(N+k, 2 N+1)=\left(\bar{C}_{13}^{(k)}-\bar{C}_{13}^{(k+1)}\right)+\left(\bar{C}_{23}^{(k)}+\bar{C}_{33}^{(k)}\right) \alpha_{k}^{(k)}-\left(\bar{C}_{23}^{(k+1)}+\bar{C}_{33}^{(k+1)}\right) \alpha_{k}^{(k+1)} \\
& F(N+k, 2 N+2)=\left[\left(\bar{C}_{23}^{(k)}+2 \bar{C}_{33}^{(k)}\right) \alpha_{2}^{(k)}-\left(\bar{C}_{23}^{(k+1)}+2 \bar{C}_{33}^{(k+1)}\right) \alpha_{2}^{(k+1)}+\left(\bar{C}_{36}^{(k)}-\bar{C}_{36}^{(k+1)}\right)\right] r_{k} \\
& F(2 N, 2 N+1)=\bar{C}_{13}^{(N)}+\left(\bar{C}_{23}^{(N)}+\bar{C}_{33}^{(N)}\right) \alpha_{1}^{(N)} \\
& F(2 N, 2 N+2)=\left[\left(\bar{C}_{23}^{(N)}+2 \bar{C}_{33}^{(N)}\right) \alpha_{2}^{(N)}+\bar{C}_{36}^{(N)}\right] r_{a} \\
& F(2 N+1,2 N+1)=\sum_{k=1}^{N}\left[\bar{C}_{11}^{(k)}+\left(\bar{C}_{12}^{(k)}+\bar{C}_{13}^{(k)}\right) \alpha_{1}^{(k)}\right] \frac{r_{k}^{2}-r_{k-1}^{2}}{2} \\
& F(2 N+1,2 N+2)=\sum_{k=1}^{N}\left[\bar{C}_{16}^{(k)}+\left(\bar{C}_{12}^{(k)}+2 \bar{C}_{13}^{(k)}\right) \alpha_{2}^{(k)}\right] \frac{r_{k}^{3}-r_{k-1}^{3}}{3} \\
& F(2 N+2,2 N+1)=\sum_{k=1}^{N}\left[\bar{C}_{16}^{(k)}+\left(\bar{C}_{26}^{(k)}+\bar{C}_{36}^{(k)}\right) \alpha_{1}^{(k)}\right] \frac{r_{k}^{3}-r_{k-1}^{3}}{3} \\
& F(2 N+2,2 N+2)=\sum_{k=1}^{N}\left[\bar{C}_{66}^{(k)}+\left(\bar{C}_{26}^{(k)}+2 \bar{C}_{36}^{(k)}\right) \alpha_{2}^{(k)}\right] \frac{r_{k}^{4}-r_{k-1}^{4}}{4}
\end{aligned}
$$




$$
\begin{gathered}
k=\overline{1, N} \\
F(2 N+1, k)=\frac{\bar{C}_{12}^{(k)}+\beta(1) \bar{C}_{13}^{(k)}}{\beta(1)+1}\left(r_{k}^{\beta(1)+1}-r_{k-1}^{\beta(1)+1}\right) \\
F(2 N+1, N+k)=\frac{\bar{C}_{12}^{(k)}+\beta(1) \bar{C}_{13}^{(k)}}{1-\beta(1)}\left(r_{k}^{-\beta(1)+1}-r_{k-1}^{-\beta(1)+1}\right) \\
F(2 N+2, k)=\frac{\bar{C}_{26}^{(k)}+\beta(1) \bar{C}_{36}^{(k)}}{\beta(1)+2}\left(r_{k}^{\beta(1)+2}-r_{k-1}^{\beta(1)+2}\right) \\
F(2 N+2, N+k)=\frac{\bar{C}_{26}^{(k)}-\beta(1) \bar{C}_{36}^{(k)}}{2-\beta(1)}\left(r_{k}^{-\beta(1)+2}-r_{k-1}^{-\beta(1)+2}\right)
\end{gathered}
$$




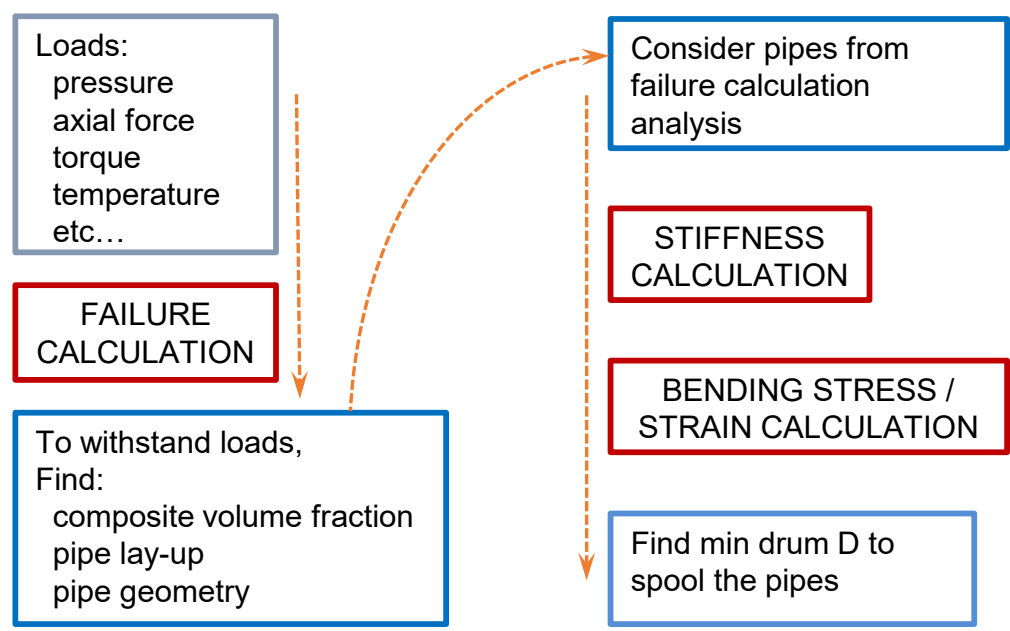

Figure 1: Composite tube design and analysis steps

\begin{tabular}{|l|}
\hline \multicolumn{1}{|c|}{ Input data } \\
\hline \multicolumn{1}{|c|}{ Pipe geometry } \\
Inner radius \\
Outer radius \\
Number of layers \\
\hline \hline \multicolumn{1}{|c|}{ Load } \\
Inner pressure \\
Outer pressure \\
Axial load \\
Thermal load \\
\hline \hline Composite \\
properties \\
Strength \\
Thermal coeffs. \\
\hline \hline Material \\
properties \\
Young's moduli \\
Shear moduli \\
Poisson's ratios \\
\hline
\end{tabular}
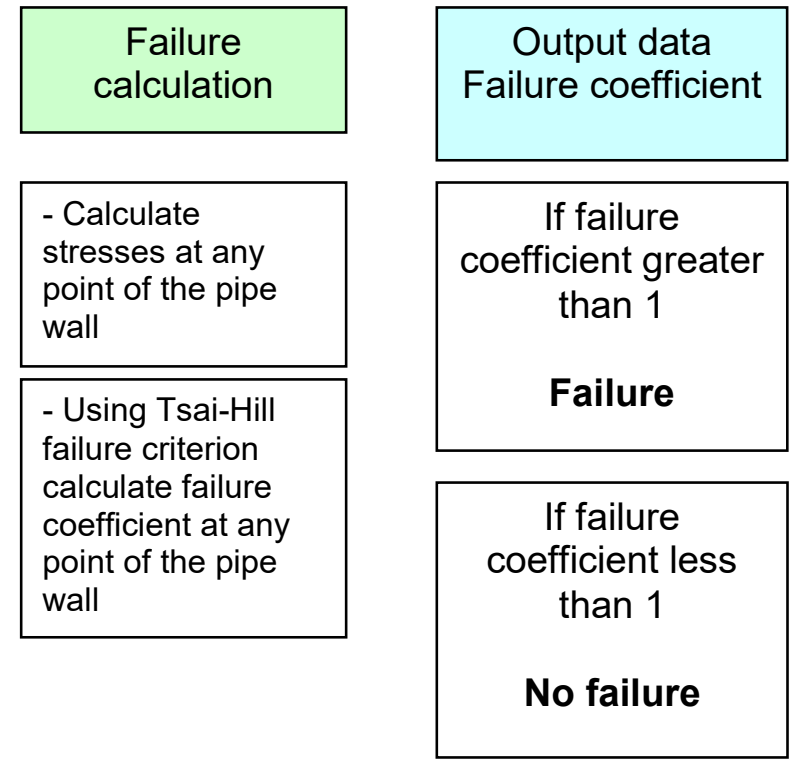

Figure 2: Software structure showing required inputs, calculations performed and outputs. 


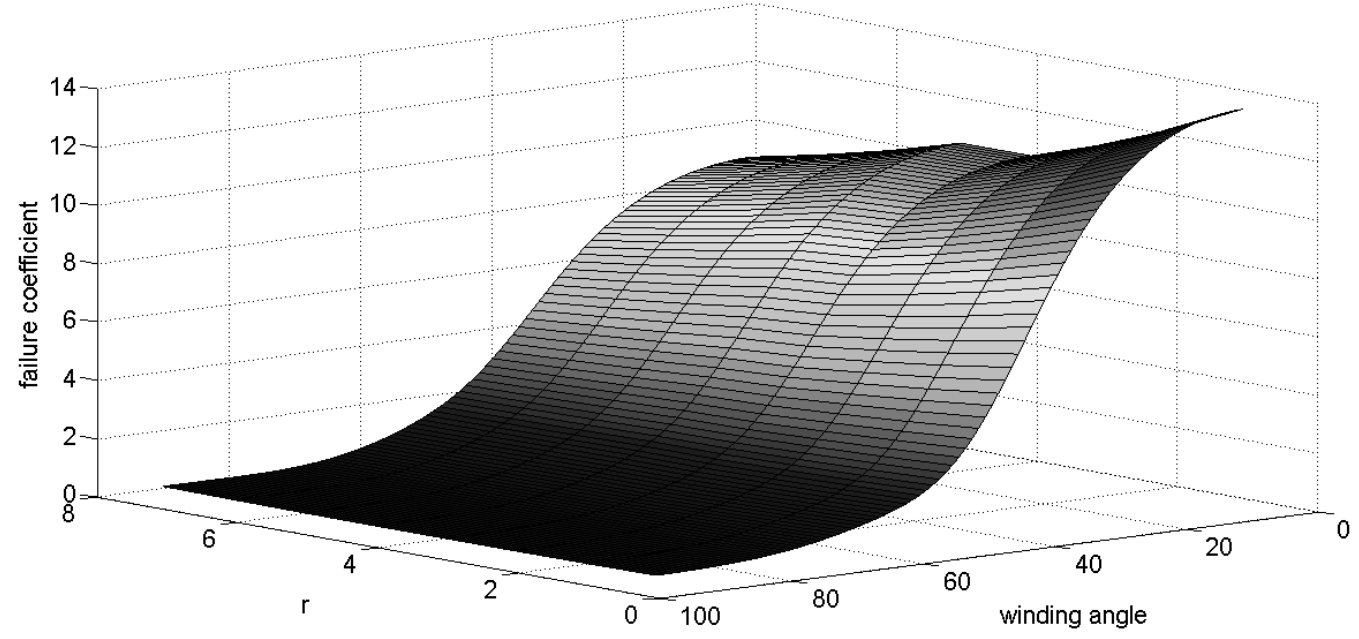

Figure 3: Failure coefficient distribution through the wall thickness for 50.8/39.4 tube with [ $[\theta /-\theta]$ layup at $60 \mathrm{MPa}$ pressure difference (inner pressure 10MPa) and no axial load

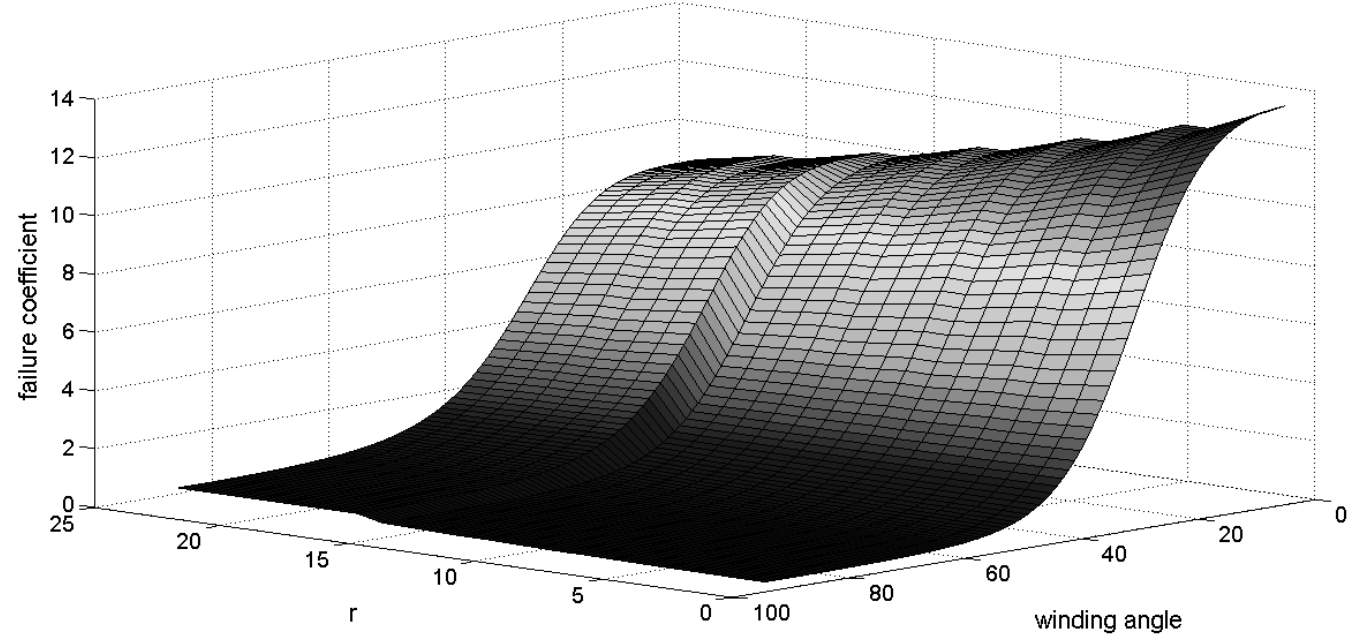

Figure 4: Failure coefficient distribution through the wall thickness for 50.8/39.4 tube with [ $[\theta /-\theta / \theta /-\theta / 0 / 0]$ layup at $60 \mathrm{MPa}$ pressure difference (inner pressure 10MPa) and no axial load 


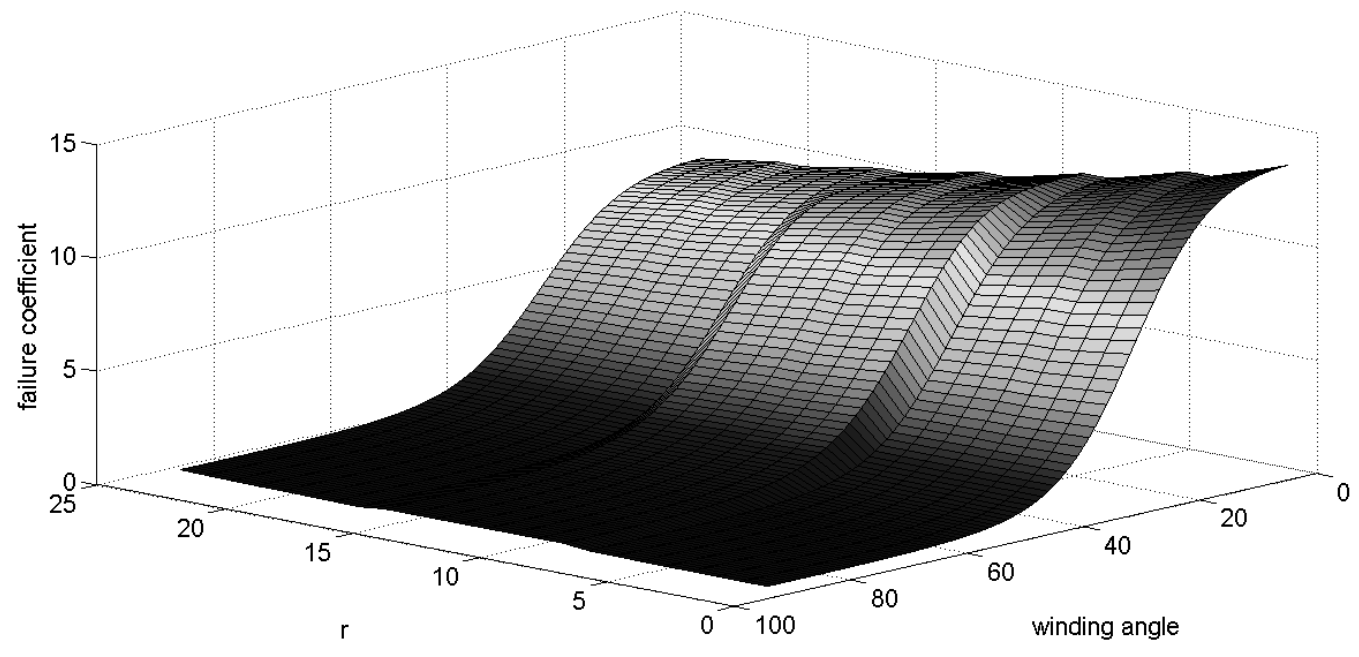

Figure 5: Failure coefficient distribution through the wall thickness for 50.8/39.4 tube with $[\theta /-\theta / 0 / 0 / \theta /-\theta]$ layup at $60 \mathrm{MPa}$ pressure difference (inner pressure $10 \mathrm{MPa}$ ) and no axial load 


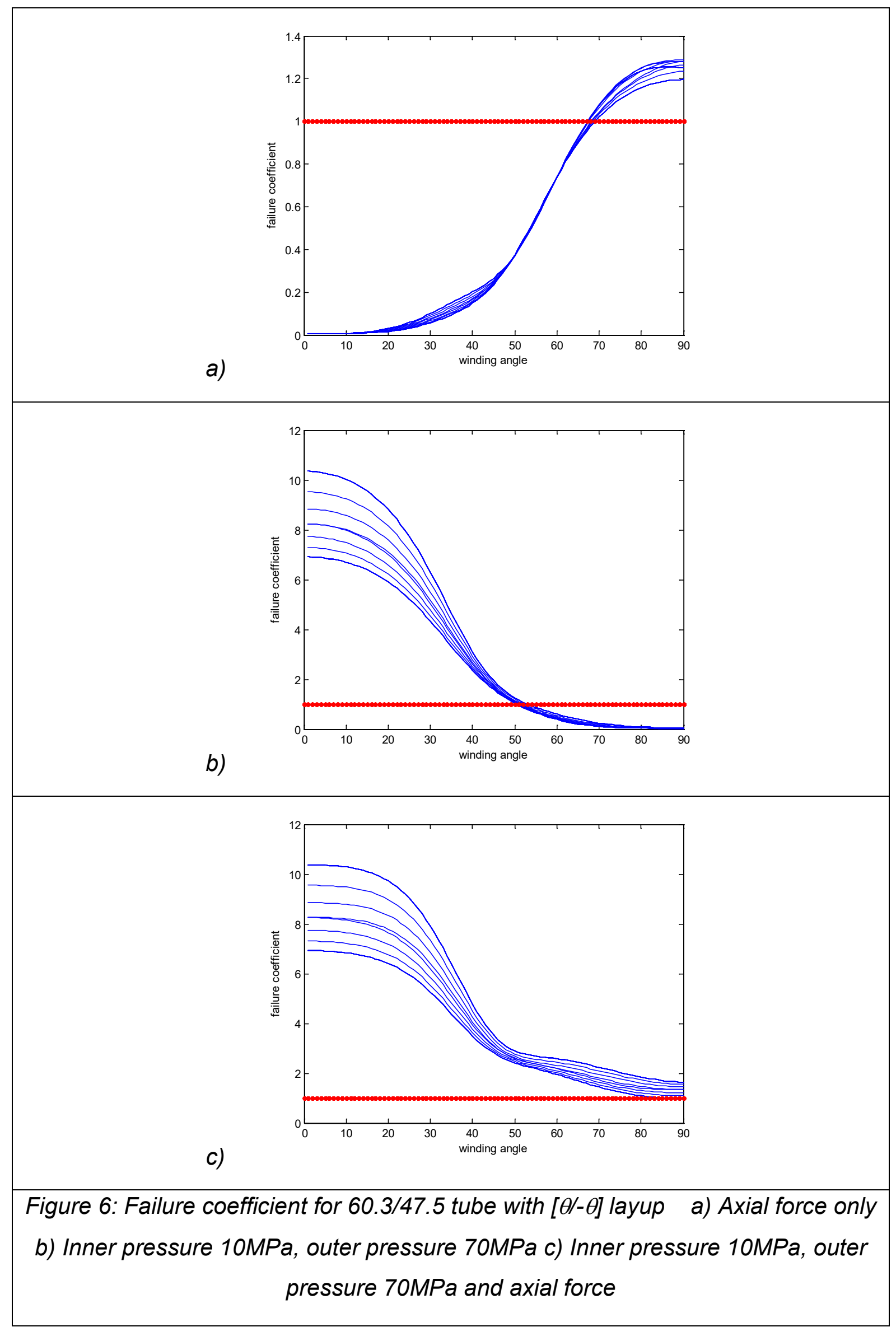


a)
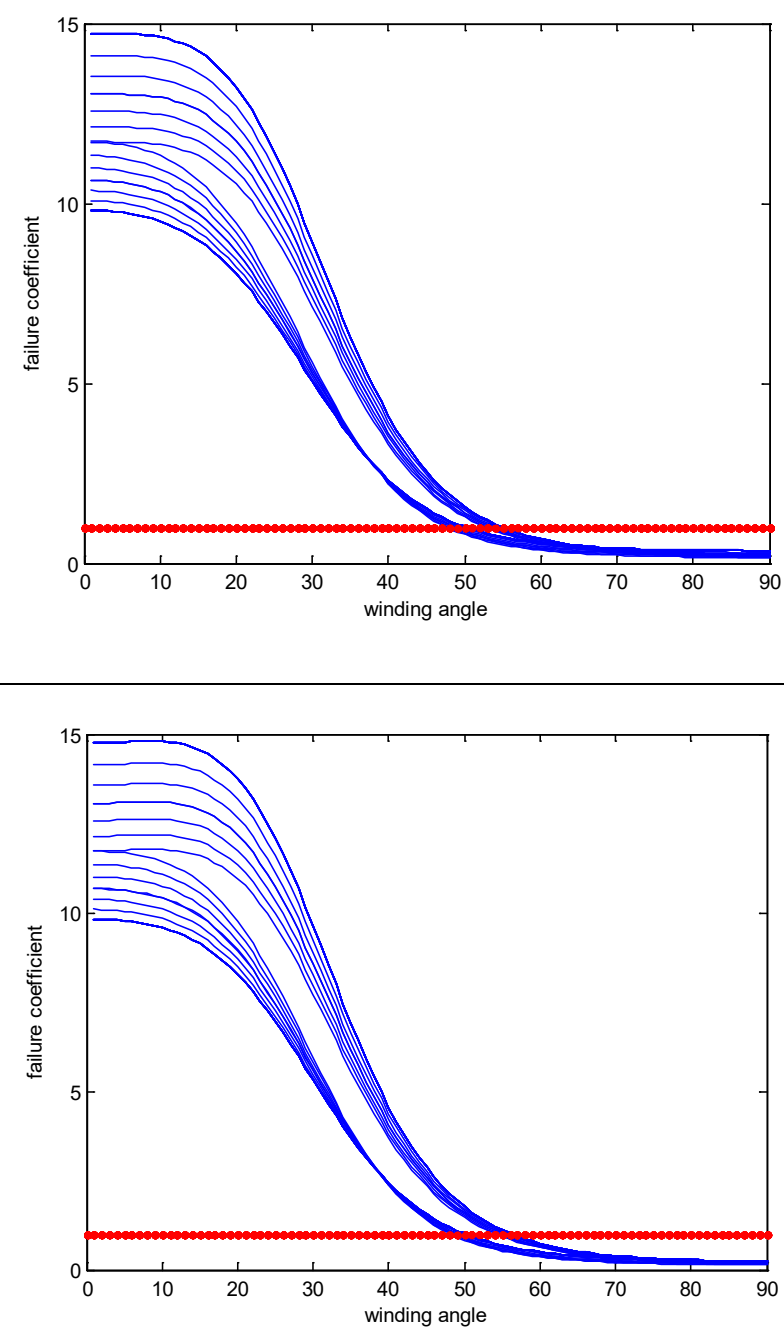

b)

c)

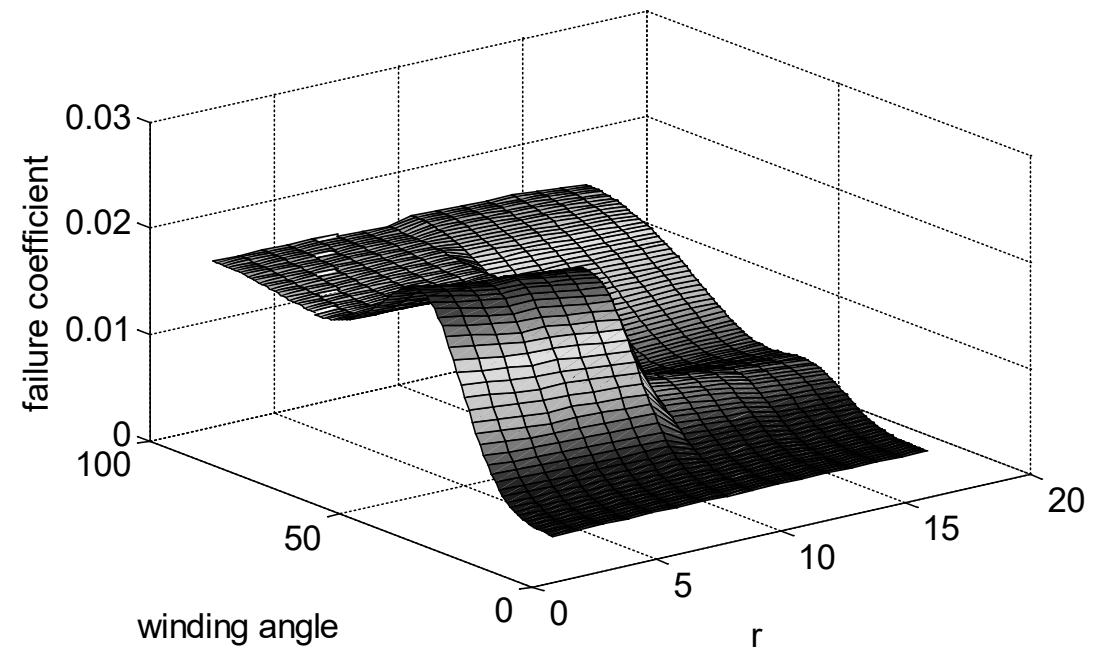

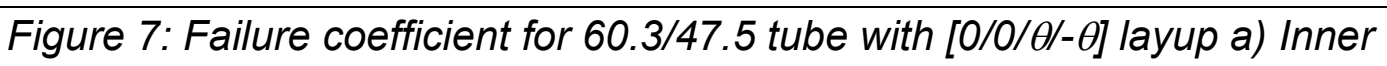
pressure $10 \mathrm{MPa}$, outer pressure $70 \mathrm{MPa}$ b) Inner pressure $10 \mathrm{MPa}$, outer pressure 70MPa and axial force c) Axial force only 


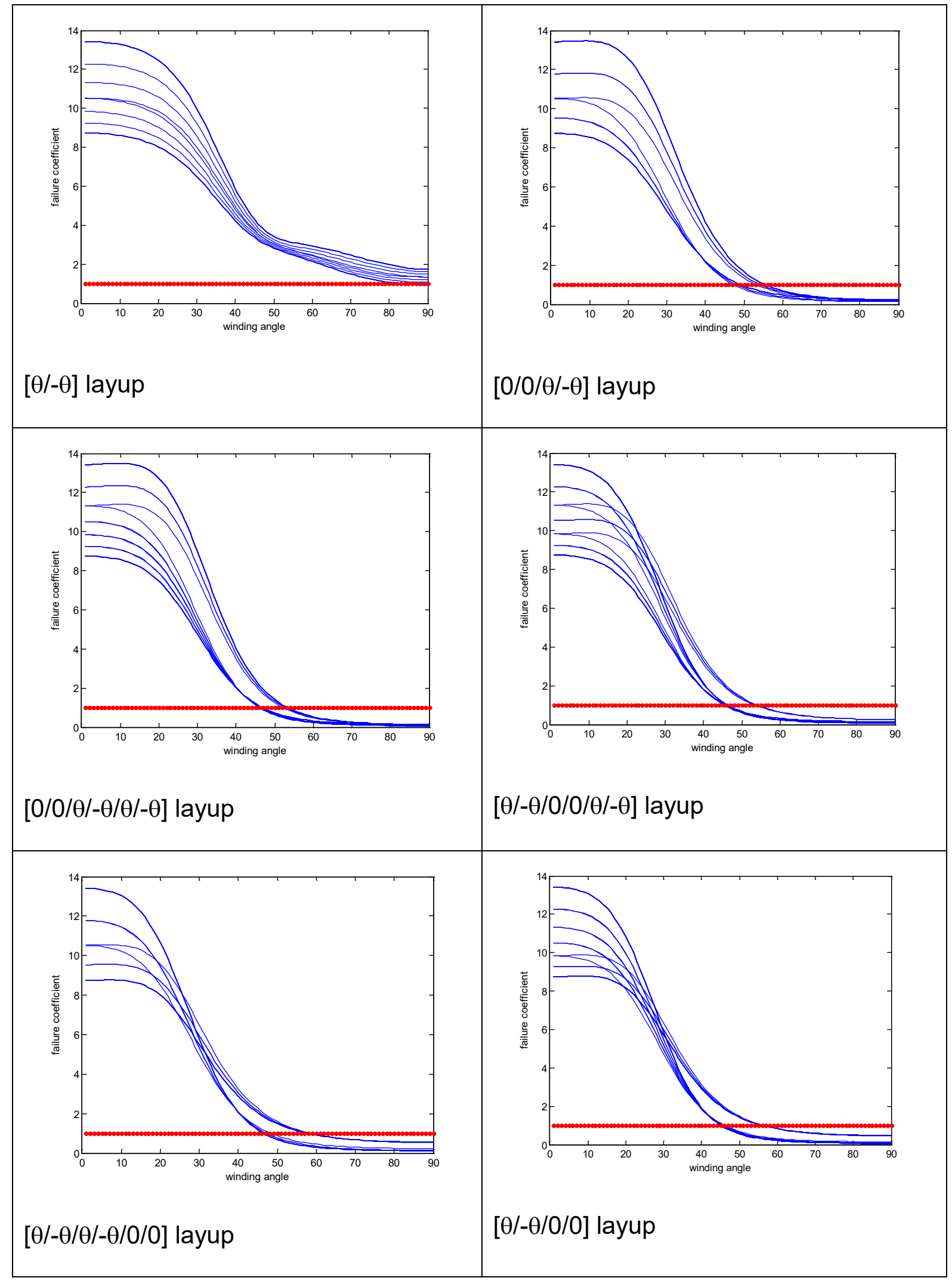

Figure 8: Failure coefficient for 50.8/39.4 tube with 60 MPa pressure difference (inner pressure 10MPa) with axial load 


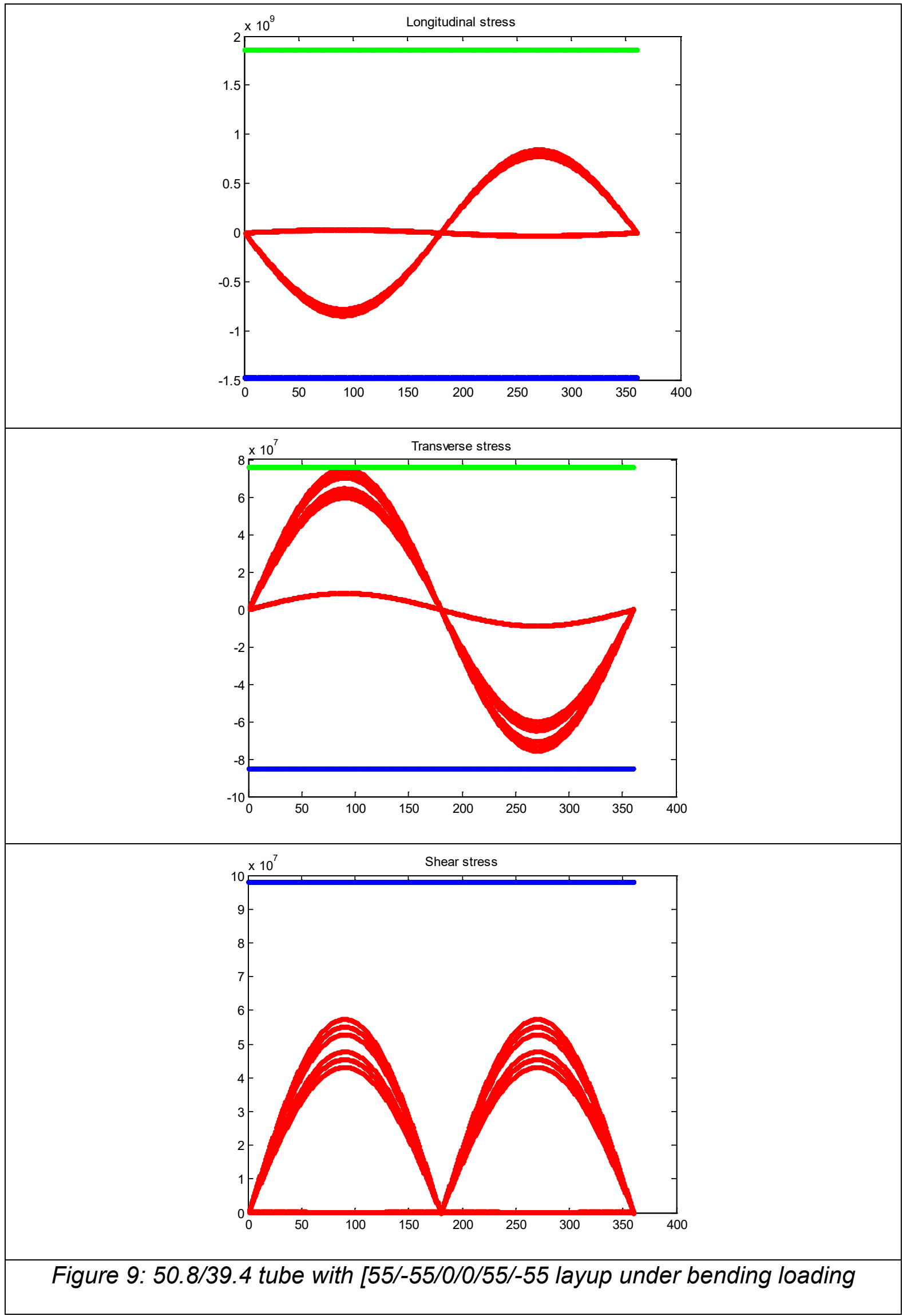




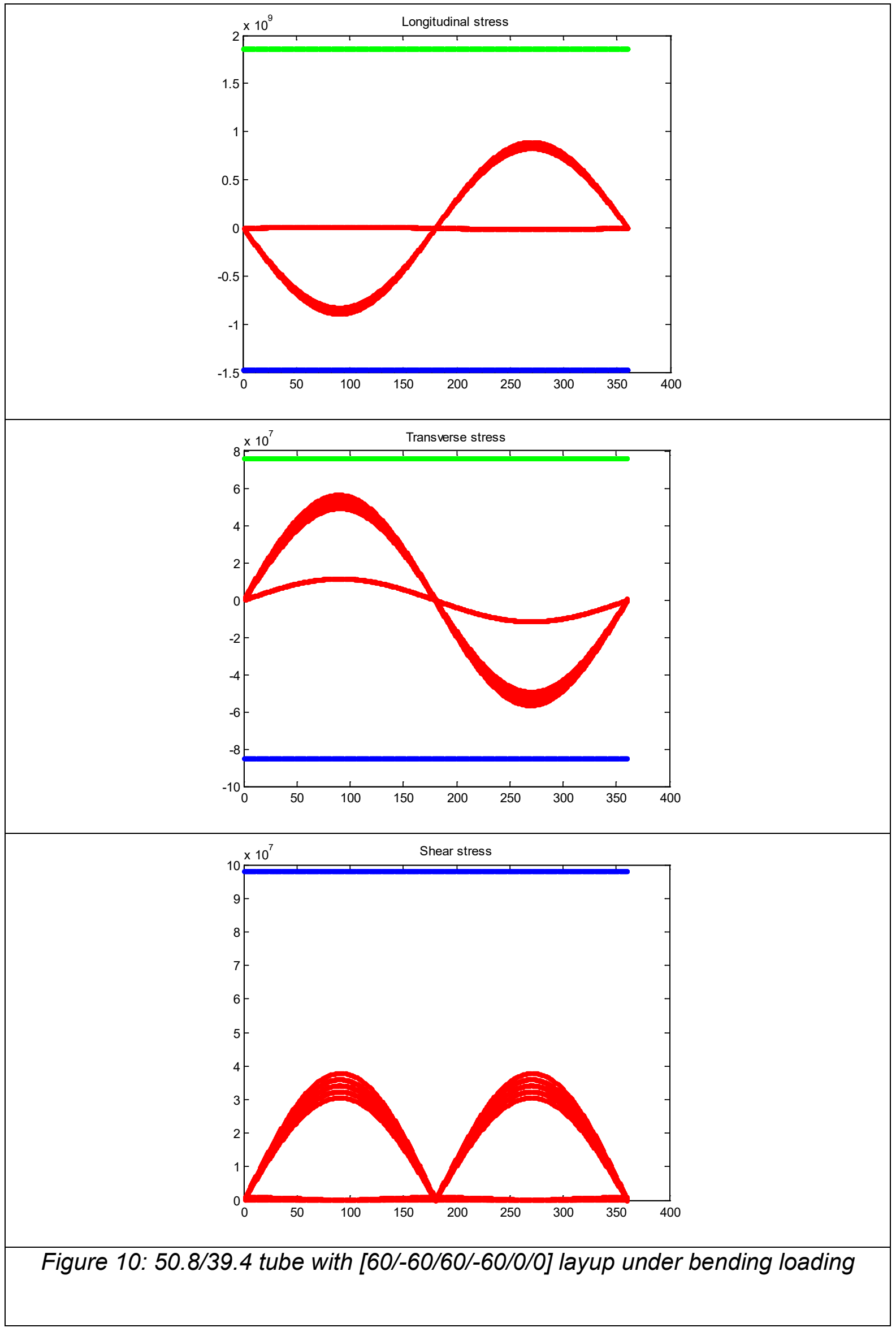




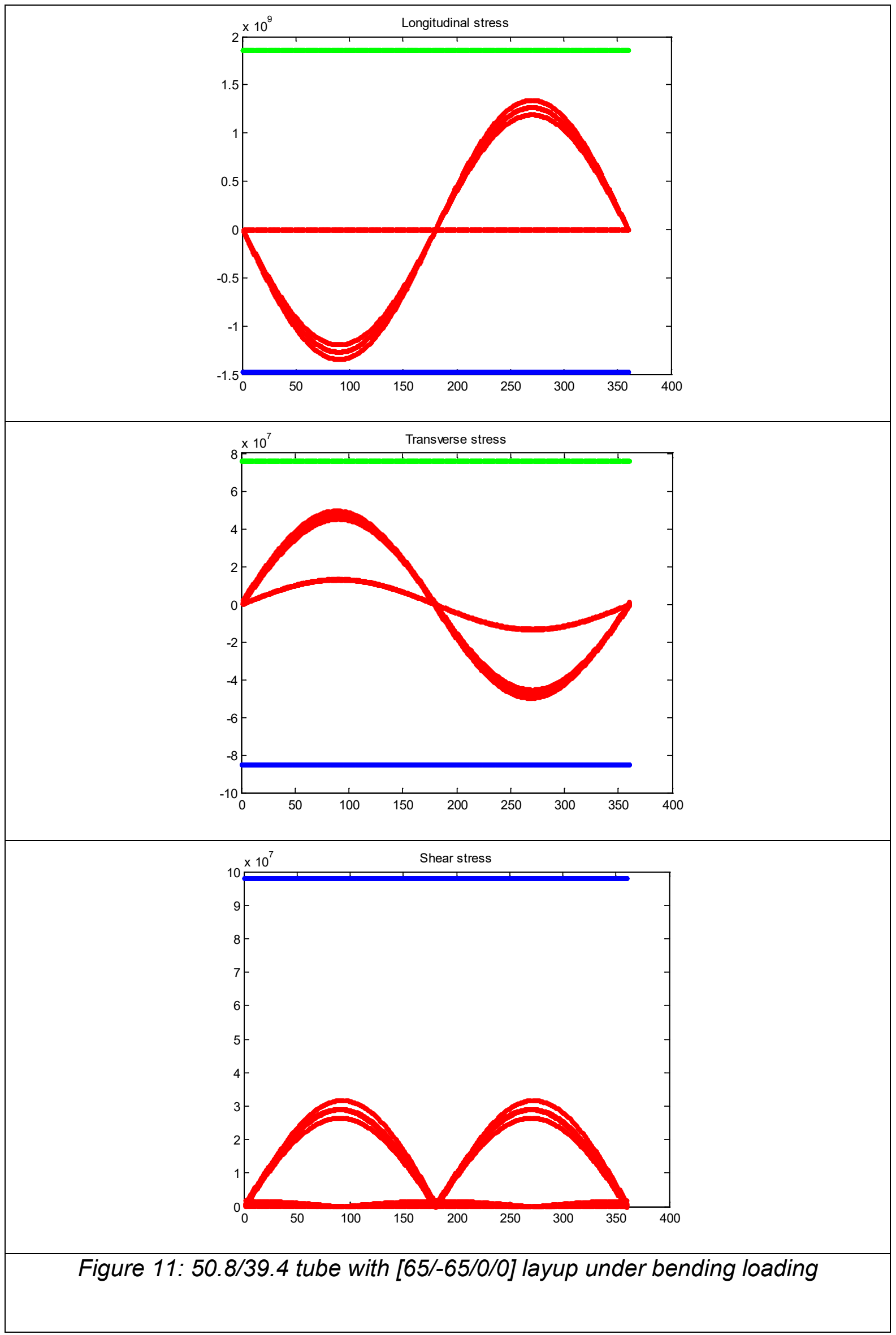



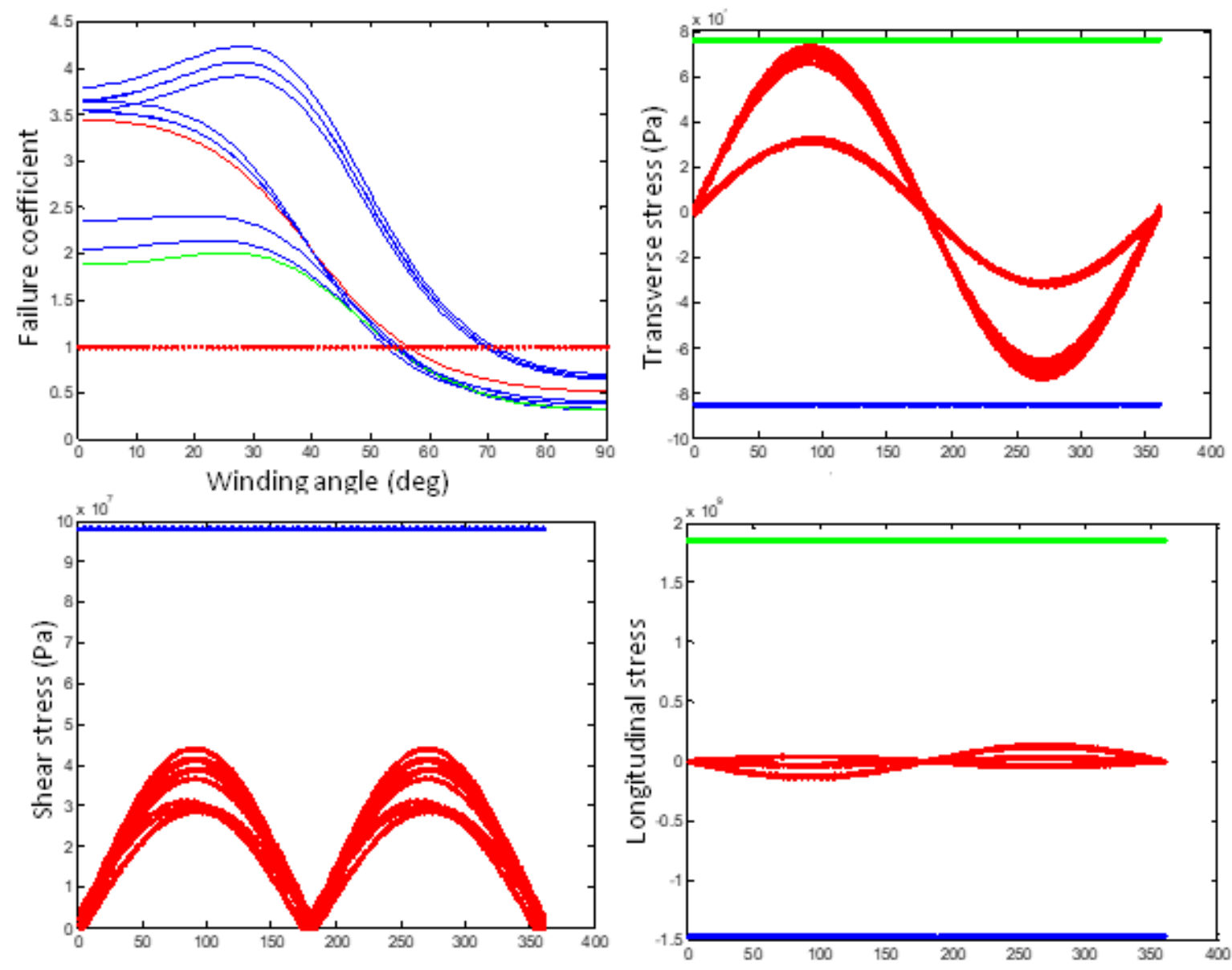

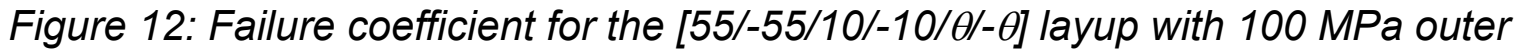
pressure and axial load (top left), longitudinal bending stress (upper right), transverse bending stress (lower left) and shear bending stress (lower right) for [55/55/10/-10/70/-70] layup 


\begin{tabular}{|l|l|l|l|l|l|l|l|l|l|l|}
\hline Property & $\begin{array}{l}\mathrm{E}_{1} \\
(\mathrm{GPa})\end{array}$ & $\begin{array}{l}\mathrm{E}_{2} \\
(\mathrm{GPa})\end{array}$ & $\begin{array}{l}\mathrm{G}_{12} \\
(\mathrm{GPa})\end{array}$ & $v_{12}$ & $v_{23}$ & $\mathrm{X}_{\mathrm{T}}$ & $\mathrm{Y}_{\mathrm{T}}$ & $\mathrm{X}_{\mathrm{C}}$ & $\mathrm{Y}_{\mathrm{C}}$ & $\mathrm{S}$ \\
\hline T300/LY5052 & 135 & 8.0 & 3.8 & 0.27 & 0.49 & 1860 & 76 & 1470 & 85 & 98 \\
\hline Steel & 205 & 205 & 77 & 0.33 & 0.33 & 483 & 483 & 483 & 483 & 290 \\
\hline
\end{tabular}

Table 1: Material properties

\begin{tabular}{|c|c|c|c|}
\hline \multicolumn{2}{|c|}{$\Delta \mathrm{P}=60 \mathrm{MPa}$} & \multicolumn{2}{c|}{$\Delta \mathrm{P}=100 \mathrm{MPa}$} \\
\hline IP 0 & OP 60 & IP 0 & OP 100 \\
\hline IP 10 & OP 70 & IP 10 & OP 110 \\
\hline
\end{tabular}

Table 2: Applied pressure loads in MPa, where IP = inner pressure and OP = outer pressure

\begin{tabular}{|c|c|}
\hline OD $(\mathrm{mm})$ & ID $(\mathrm{mm})$ \\
\hline 50.8 & 39.4 \\
\hline 60.3 & 47.5 \\
\hline 66.7 & 53.9 \\
\hline
\end{tabular}

Table 3: Composite pipe geometries 


\begin{tabular}{|c|c|c|c|c|}
\hline Layup & $\begin{array}{c}\text { Pressure difference (MPa) } \\
\text { with IP } 10 \mathrm{MPa}\end{array}$ & $\begin{array}{l}\text { OD } 50.8 \mathrm{~mm} \\
\text { ID } 39.4 \mathrm{~mm}\end{array}$ & $\begin{array}{l}\text { OD } 60.3 \mathrm{~mm} \\
\text { ID } 47.5 \mathrm{~mm}\end{array}$ & $\begin{array}{l}\text { OD } 66.7 \mathrm{~mm} \\
\text { ID } 53.9 \mathrm{~mm}\end{array}$ \\
\hline \multirow{2}{*}[\theta/-\theta]{} & 60 & $58^{\circ}-90^{\circ}$ & $60^{\circ}-90^{\circ}$ & $62^{\circ}-90^{\circ}$ \\
\hline & 100 & $69^{\circ}-90^{\circ}$ & $69^{\circ}-90^{\circ}$ & $70^{\circ}-90^{\circ}$ \\
\hline \multirow{2}{*}[0/0/\theta/-\theta]{} & 60 & $55^{\circ}-90^{\circ}$ & $55^{\circ}-90^{\circ}$ & $58^{\circ}-90^{\circ}$ \\
\hline & 100 & $85^{\circ}-90^{\circ}$ & $80^{\circ}-90^{\circ}$ & None \\
\hline \multirow{2}{*}{$\begin{array}{l}{[0 / 0 / \theta /-\theta / \theta /-} \\
\theta]\end{array}$} & 60 & $52^{\circ}-90^{\circ}$ & $53^{\circ}-90^{\circ}$ & $55^{\circ}-90^{\circ}$ \\
\hline & 100 & $62^{\circ}-90^{\circ}$ & $63^{\circ}-90^{\circ}$ & $65^{\circ}-90^{\circ}$ \\
\hline \multirow{2}{*}{$\begin{array}{l}{[\theta /-\theta / 0 / 0 / \theta /-} \\
\theta]\end{array}$} & 60 & $53^{\circ}-90^{\circ}$ & $54^{\circ}-90^{\circ}$ & $56^{\circ}-90^{\circ}$ \\
\hline & 100 & $70^{\circ}-90^{\circ}$ & $70^{\circ}-90^{\circ}$ & $75^{\circ}-90^{\circ}$ \\
\hline \multirow{2}{*}{$\begin{array}{l}{[\theta /-\theta / \theta /-} \\
\theta / 0 / 0]\end{array}$} & 60 & $57^{\circ}-90^{\circ}$ & $56^{\circ}-90^{\circ}$ & $60^{\circ}-90^{\circ}$ \\
\hline & 100 & None & None & None \\
\hline \multirow{2}{*}[\theta/-\theta/0/0]{} & 60 & $57^{\circ}-90^{\circ}$ & $60^{\circ}-90^{\circ}$ & $60^{\circ}-90^{\circ}$ \\
\hline & 100 & None & None & None \\
\hline
\end{tabular}

Table 4: Acceptable composite layups and fiber angles to withstand pressure load 


\begin{tabular}{|c|c|c|c|c|}
\hline Layup & $\begin{array}{l}\text { Pressure difference } \\
\qquad(\mathrm{MPa}) \\
\text { with IP } 10 \mathrm{MPa}\end{array}$ & $\begin{array}{c}\text { OD } \\
50.8 \mathrm{~mm} \\
\text { ID } 39.4 \mathrm{~mm}\end{array}$ & $\begin{array}{l}\text { OD } 60.3 \mathrm{~mm} \\
\text { ID } 47.5 \mathrm{~mm}\end{array}$ & $\begin{array}{l}\text { OD } 66.7 \mathrm{~mm} \\
\text { ID } 53.9 \mathrm{~mm}\end{array}$ \\
\hline \multirow{2}{*}[\theta/-\theta]{} & 60 & None & None & None \\
\hline & 100 & None & None & None \\
\hline \multirow{2}{*}[0/0/\theta/-\theta]{} & 60 & $55^{\circ}-90^{\circ}$ & $55^{\circ}-90^{\circ}$ & $60^{\circ}-90^{\circ}$ \\
\hline & 100 & $70^{\circ}-90^{\circ}$ & $64^{\circ}-90^{\circ}$ & $80^{\circ}-90^{\circ}$ \\
\hline \multirow{2}{*}[0/0/\theta/-\theta/\theta/-\theta]{} & 60 & $55^{\circ}-90^{\circ}$ & $55^{\circ}-90^{\circ}$ & $57^{\circ}-90^{\circ}$ \\
\hline & 100 & $64^{\circ}-90^{\circ}$ & $65^{\circ}-90^{\circ}$ & $68^{\circ}-90^{\circ}$ \\
\hline \multirow{2}{*}[\theta/-\theta/0/0/\theta/-\theta]{} & 60 & $55^{\circ}-90^{\circ}$ & $55^{\circ}-90^{\circ}$ & $58^{\circ}-90^{\circ}$ \\
\hline & 100 & $70^{\circ}-90^{\circ}$ & $73^{\circ}-90^{\circ}$ & $75^{\circ}-90^{\circ}$ \\
\hline \multirow{2}{*}[\theta/-\theta/\theta/-\theta/0/0]{} & 60 & $57^{\circ}-90^{\circ}$ & $60^{\circ}-90^{\circ}$ & $60^{\circ}-90^{\circ}$ \\
\hline & 100 & None & None & None \\
\hline \multirow{2}{*}[\theta/-\theta/0/0]{} & 60 & $58^{\circ}-90^{\circ}$ & $60^{\circ}-90^{\circ}$ & $67^{\circ}-90^{\circ}$ \\
\hline & 100 & None & None & None \\
\hline
\end{tabular}

Table 5: Acceptable composite layups and fiber angles to withstand the pressure load and axial force 


\begin{tabular}{|l|c|c|c|}
\hline Layup & $\begin{array}{c}\text { OD 50.8mm } \\
\text { ID 39.4mm }\end{array}$ & $\begin{array}{c}\text { OD 60.3mm } \\
\text { ID 47.5mm }\end{array}$ & $\begin{array}{c}\text { OD 66.7mm } \\
\text { ID 53.9mm }\end{array}$ \\
\hline$[\theta /-\theta]$ & $38^{\circ}-40^{\circ}$ & None & None \\
\hline$[0 / 0 / \theta /-\theta]$ & None & None & None \\
\hline$[0 / 0 / \theta /-\theta / \theta /-\theta]$ & None & None & None \\
\hline$[\theta /-\theta / 0 / 0 / \theta /-\theta]$ & $55^{\circ}-65^{\circ}$ & None & None \\
\hline$[\theta /-\theta / \theta /-\theta / 0 / 0]$ & $35^{\circ}-65^{\circ}$ & $50^{\circ}-65^{\circ}$ & None \\
\hline$[\theta /-\theta / 0 / 0]$ & $35^{\circ}-65^{\circ}$ & $50^{\circ}-65^{\circ}$ & $55^{\circ}-60^{\circ}$ \\
\hline
\end{tabular}

Table 6: Acceptable composite layups and fiber angles to withstand bending load (drum diameter $2.84 m$ )

\begin{tabular}{|c|c|c|c|c|}
\hline \multirow[b]{2}{*}{ Layup } & \multirow{2}{*}{$\begin{array}{l}\text { Young's modulus } \\
(\mathrm{GPa})\end{array}$} & \multicolumn{3}{|c|}{ Bending stiffness $\left(* 10^{3} \mathrm{~N} / \mathrm{m}^{2}\right)$} \\
\hline & & $\begin{array}{l}\text { OD } 50.8 \mathrm{~mm} \\
\text { ID } 39.4 \mathrm{~mm}\end{array}$ & $\begin{array}{l}\text { OD } 60.3 \mathrm{~mm} \\
\text { ID } 47.5 \mathrm{~mm}\end{array}$ & $\begin{array}{l}\text { OD } 66.7 \mathrm{~mm} \\
\text { ID } 53.9 \mathrm{~mm}\end{array}$ \\
\hline$[40 /-40]$ & 11.5306 & 38.48 & 73.6 & 102.8 \\
\hline$[60 /-60]$ & 8.3775 & 27.9 & 53.5 & 74.7 \\
\hline$[70 /-70]$ & 8.0427 & 26.8 & 51.4 & 71.7 \\
\hline$[0 / 0 / 60 /-60]$ & 67.6879 & 225.9 & 433.8 & 609.2 \\
\hline [0/0/85/-85] & 67.4851 & 225.2 & 432.4 & 607.4 \\
\hline$[0 / 0 / 55 /-55 / 55 /-55]$ & 47.2871 & 157.8 & 303.3 & 426.7 \\
\hline$[0 / 0 / 65 /-65 / 65 /-65]$ & 46.8756 & 156.5 & 300.7 & 423 \\
\hline$[55 /-55 / 0 / 0 / 55 /-55]$ & 50.833 & 169.7 & 324.6 & 453.2 \\
\hline$[60 /-60 / 0 / 0 / 60 /-60]$ & 50.585 & 168.9 & 323 & 451 \\
\hline [75/-75/0/0/75/-75] & 50.3314 & 168 & 321.4 & 448.8 \\
\hline$[60 /-60 / 60 /-60 / 0 / 0]$ & 54.1413 & 180.7 & 344.4 & 477.7 \\
\hline$[85 /-85 / 85 /-85 / 0 / 0]$ & 53.8977 & 179.9 & 342.8 & 475.5 \\
\hline$[60 /-60 / 0 / 0]$ & 75.6896 & 252.6 & 481.8 & 669.1 \\
\hline$[85 /-85 / 0 / 0]$ & 75.5109 & 252 & 480.6 & 667.5 \\
\hline$[55 /-55 / 10 /-10 / 70 /-70]$ & 28.3183 & 94.5 & 180.8 & 252.5 \\
\hline
\end{tabular}

Table 7: Young's modulus and bending stiffness 


\begin{tabular}{|l|c|c|c|}
\hline Layup & $\begin{array}{c}\text { OD 50.8mm } \\
\text { ID 39.4mm }\end{array}$ & $\begin{array}{c}\text { OD 60.3mm } \\
\text { ID } 47.5 \mathrm{~mm}\end{array}$ & ID $53.9 \mathrm{~mm}$ \\
\hline$[\theta /-\theta]$ & None & None & None \\
\hline$[0 / 0 / \theta /-\theta]$ & None & None & None \\
\hline$[0 / 0 / \theta /-\theta / \theta /-\theta]$ & None & None & None \\
\hline$[\theta /-\theta / 0 / 0 / \theta /-\theta]$ & $55^{\circ}$ & None & None \\
\hline$[\theta /-\theta / \theta /-\theta / 0 / 0]$ & $57^{\circ}-65^{\circ}$ & $60^{\circ}-65^{\circ}$ & None \\
\hline$[\theta /-\theta / 0 / 0]$ & $58^{\circ}-65^{\circ}$ & $60^{\circ}-65^{\circ}$ & None \\
\hline
\end{tabular}

Table 8: Acceptable composite layups and fiber angles to withstand bending (drum diameter $2.84 \mathrm{~m}$ ) and pressure load (pressure difference of 60MPa, with 10MPa inner pressure) 